Session 2438

\title{
The VisTE Project: Visualization for Improved Technological and Scientific Literacy
}

\author{
Eric N. Wiebe, Aaron C. Clark, Miriam Ferzli and Rachel McBroom \\ NC State University, Raleigh, NC
}

\begin{abstract}
Visualization in Technology Education (VisTE) is a standards-based initiative designed to promote the use of graphic visualization among grade 8-12 students to improve their higher order thinking, communication skills, and understanding of science, technology, engineering, and mathematics (STEM) topics. By using simple and complex visualization tools, students can conduct research, analyze, solve problems, and communicate major topics identified in the new ITEA Standards for Technological Literacy (STL) as well as topics aligned with national mathematics and science standards. Unfortunately, rigorously tested instructional materials to support such activities do not yet exist. Over three years, the project team will develop 12 discrete units. Units will encompass areas such as biotechnology, medical technology, communications, transportation, power \& energy, and construction. While the curriculum is not developed for the post-secondary level, it is expected to have an impact on the students' understanding of key technologies and their ability to apply graphic communication tools in the exploration and conveyance of technology and engineering concepts. This presentation will provide an overview of the project.
\end{abstract}

\section{Background}

On April 2000, the International Technology Education Association (ITEA) reported in a document titled Standards for Technological Literacy: Content for the Study of Technology that America's students urgently need to develop a deeper knowledge of the nature, creation, and potentials of technology and its symbiotic role in human society, as well as develop a broader range of technological skills ${ }^{1}$. The Technology for All Americans Project, a branch of the ITEA that helped create the Standards for Technological Literacy (STL), issued a "call to action" to a variety of stakeholders to help cultivate technological literacy and to recognize technology education as an essential core field of study in our nation's secondary schools. Toward this end, it has also called for the creation and/or modification of a variety of instructional materials to better reflect the new standards. The Visualization in Technology Education (VisTE) project presented in this paper addresses this need by developing materials that will enhance the technology education curriculum. These materials provide activities requiring students' use of graphic communication tools to convey scientific and technical data that are aligned with the Standards for Technological Literacy (STL), along with secondary mathematics and science curriculum development standards.

The earliest efforts by project investigators to use computer graphics visualization in technology education began with the development of a post-secondary course in scientific visualization for undergraduate engineering and science students ${ }^{2}$. Later activities in revising NC's secondary technical graphics curriculum led investigators to believe that computer graphics literacy could play a key role in vocational and technical education reform. Since 1995, the project investigators, with the assistance of Carl Perkins federal funds and in partnership with the NC Department of Public Instruction (NCDPI), several school systems, and a leading community college, have developed and piloted similar materials through the development of a two-year high

Proceedings of the 2003 American Society for Engineering Education Annual Conference \& Exposition. Copyright 2003, American Society for Engineering Education 
school curriculum for statewide use, currently offered under technology education. This work has yielded a two-year curriculum and a website maintained at NC State University consisting of 26 activities tied to the curriculum ${ }^{3,4}$. This research has led to a number of findings concerning the potential of VisTE in technology education ${ }^{5}$, including that:

- It is feasible for Technology Education teachers, working in conjunction with their science counterparts, to integrate science content into a VisTE framework

- Mathematics can be integrated into VisTE activities.

- VisTE projects naturally lend themselves to design/problem-solving oriented activities, helping structure classroom activities around individual and group exploration of how to communicate technical and scientific information effectively.

All three of these findings emphasize the critical role of design and problem-solving learning experiences in science, mathematics, and technology for the development of students planning careers in engineering.

\section{The VisTE Project}

The VisTE project will develop 12 stand alone units, promoting graphics visualization skills which align with STEM standards, integrate science and mathematics into technology education, and can be used nationally. The independent nature of these units will allow for their adoption into a number of existing technology education courses. Similarly, the units also lend themselves to cross-curricular integration, making them accessible to an even broader audience of teachers and students in mathematics, science, and technology education curricula.

In consultation with the advisory panel, the authors have identified 12 applied design problems, in the form of "design briefs," to be distributed evenly across the technology education curriculum. Topics chosen from these content areas will be linked directly to the STL. In turn, the advisory panel will establish outcomes and student learning objectives for each unit to be developed. All unit projects will be grounded in "higher order" technology content standards, particularly those of Standard 17 - "information and communications technology." The traditional technology education principles that apply to these materials are those that promote students' development of skills in computer technology, with a direct emphasis on multimedia (data harvesting, manipulation, and output) and visualization.

\section{Conceptual Framework}

Despite recognition of the many benefits of technical graphics communication instruction in grades 9-12 technology education, there are as of yet no rigorous, well-tested, standards-based, nationally distributed materials to support such instruction in our nation's high schools. Even as the nation's high school technology education classes have begun using sophisticated graphics tools to create 2D documents and 3D models, many have remained narrowly focused on traditional applied technology areas. Graphics tools continue to be used primarily to document completed designs of architectural, civil, or mechanically engineered products. The graphics are used in the creation of tangible objects rather than for the exploration of higher order scientific, mathematical, or technological concepts. Desktop publishing and multimedia software and hardware are being used as forms of communications technology but not as legitimate sources of knowledge in their own right. Finally, although students may have been encouraged to use computer graphics tools to design a graphic for a project, the constraints guiding the design have 
usually been based primarily on aesthetic concerns or highly localized constraints (e.g., the final image should be $7 \times 9$ inches), rather than tied to a larger framework of effective graphic communication.

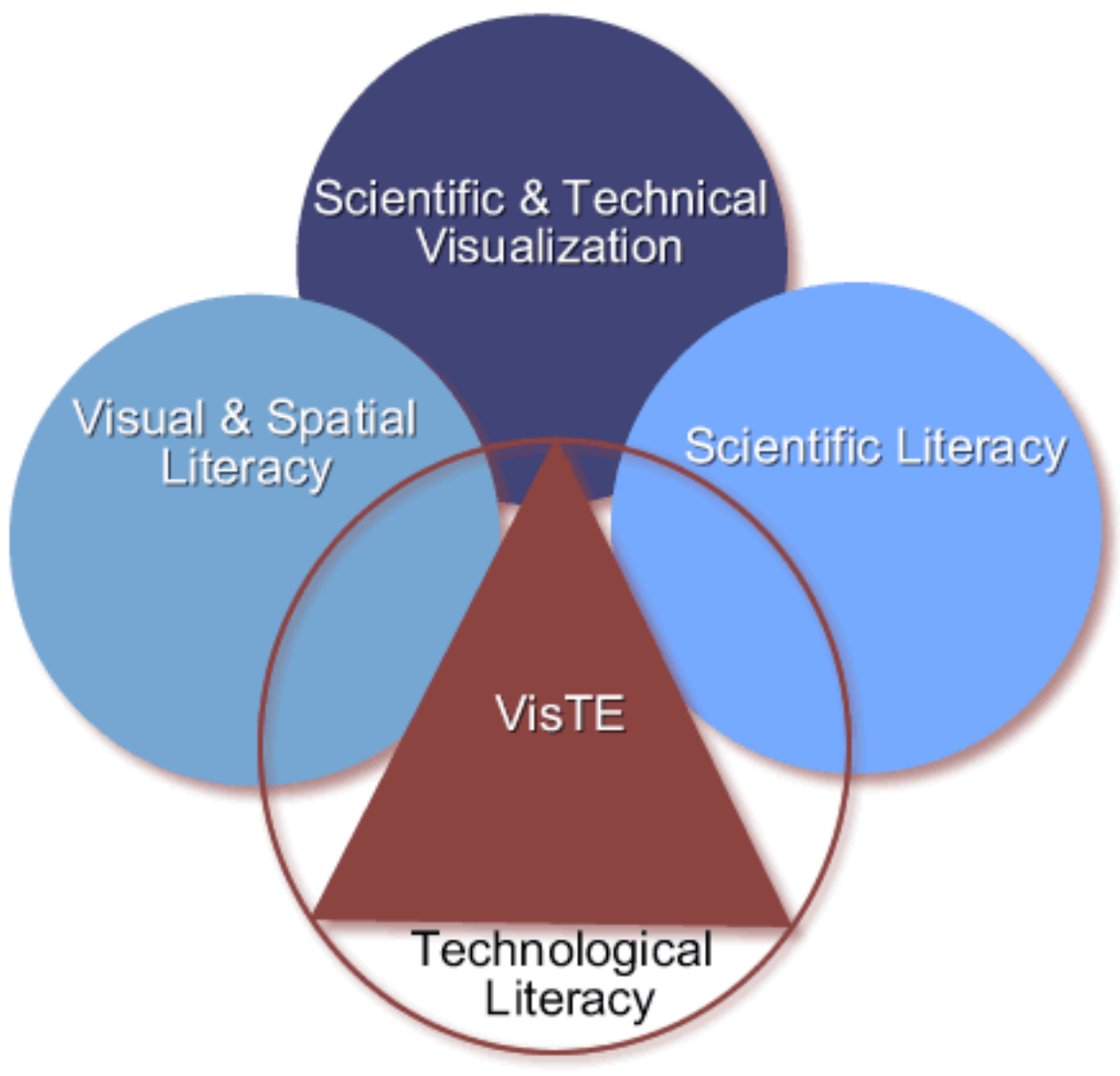

Figure 1. Conceptual Framework of the VisTE Instructional Materials

The VisTE project, however, takes a different approach as to how graphic communication can be integrated into technology education. Its project goals aim to promote technological literacy through the use of scientific and technical visualization tools and techniques (Figure 1). This approach recognizes that developing visual and spatial literacy and scientific literacy be part of the process. Each VisTE activity presents the problem of communicating about a technical or scientific topic using visualization tools. The design problem, therefore, is a problem in graphic communications. To successfully address this design problem, students have to:

- Understand the technological, scientific and mathematical concepts that underlie the topic of interest

- Decompose the topic into the essential ideas that are to be communicated

- Understand who the audience is and what the medium for communication will be

- Strategize and design the graphics needed for communication

- Select and use graphics technologies to create the communication elements

- Be able to constructively evaluate the finished design created by themselves or others 
Each of the projects use a 'design brief' approach to provide students with opportunities to engage in two basic areas of technology: the technology about which they are communicating and the graphics technology needed to create the communication. Previous experience with these types of activities demonstrate that students may think they have full command of a science or technology topic, yet once they start the process of constructing the graphic communications, knowledge gaps appear. The appearance of these gaps in the context of a problem-solving activity provides a powerful motivator for the student to fill the knowledge gaps. The process of expressing science and technology concepts in formats other than in written, verbal, or mathematical form provides an alternative approach to learning; one that many students have few opportunities to experience.

The use of a graphic communication provides a powerful motivator for students to explore the science and technology topics in depth, while in turn, science and technology topics provide a meaningful context for the creation of the graphic communication. Typically, when graphics technology is being explored in the classroom, the 'grist' used for the creation of the graphic is canned, clearly secondary to the activity, or 'whatever the student wants to do'. The lack of equity between the graphics technology being explored and the subject of the graphic does not provide for a realistic or motivating context for graphics creation. In the VisTE activities there is a balance between these two technology areas and, therefore, a strong, realistic context for the all graphics projects. Here, students are exploring and developing skills with graphics technology, but in the context of salient and meaningful science and technology content.

Rather than based simply on aesthetic considerations, the student design of the graphic communications is guided by a number of factors. As with any other design problem, a successful solution takes into account the limitations of the tools and materials being used in the design. Activities are structured to provide students with increasingly open-ended design problems. Initially the design constraints are more controlled while the students are developing an understanding about the possibilities of the graphic technologies. Later, more open-ended design problems provide students the challenge of selecting and applying the appropriate tools and techniques. Just as important as a mastery of the graphics technologies is an understanding of basic graphic communication principles. These principles are introduced to students in introductory units and reinforced throughout the remaining units. Rubrics supplied with each of the projects and teacher training materials provide support for constructive evaluation of design solutions and guidance for revision.

The design process encourages a team-based approach to problem solving, which centers on the social constructivist approach of individual knowledge construction situated in the social context in meaning making. Finally, the design briefs are inherently multidisciplinary. Activities will be adaptable for team-teaching by instructors from a variety of backgrounds, helping to ensure that the VisTE project will promote diversity in all aspects of the instructional materials. VisTE project PIs will identify design briefs that proactively address issues of concern to minority students and to females, to make these materials as attractive and accessible as possible to students traditionally underrepresented in technology education classes. Project investigators and panel members are committed to broadening the Science, Technology, Engineering and Mathematics (STEM) student base that would eventually be reflected in the workforce. 


\section{Learning Experiences}

Each unit will ensure that students will develop competencies in a wide range of graphics technologies. This can be accomplished through computer software such as: 2-D graphing and charting; 2-D object-oriented graphics-both static and dynamic; 2-D image processing; geographic information systems (GIS); 3-D modeling and animation; and multimedia presentation software. Students will also work with such allied technologies as remote sensing; geographic positioning systems (GPS); medical imaging; digital photography and scanning; video production; and local and wide-area networking.

By engaging in these design activities, students will gain mastery in a wide variety of computer data input and output devices that handle audio, video, static and animated graphics, and alphanumeric-based information. These experiences go beyond narrowly focused skill activities with graphics software, including work with:

- Data manipulation and management abilities with the use of spreadsheet tools.

- Skills in graphic generation and manipulation linked to design process skills, requiring the use of higher order thinking and ability to effectively communicate to multiple audiences.

- Mastery of integrated process skills with the ability to acquire, process, and interpret data.

- Ability to identify variables and their relationships and how to create and formulate models from data.

- Ability to perform technological design and apply this knowledge in the creation of appropriate visualizations from the materials and tools at hand.

All units will include a historical background of the role of VisTE topics in society, societal/environmental implications of the technology/science being explored, and how technology changes can respond to societal/environmental problems. The instructor's version will contain additional reference sources and discussion topics.

By providing a context for STEM topics within design-oriented problems, these units will ensure that students will have the opportunity to experience these subjects in ways usually not supported in the classroom. STEM concepts can be manifested and manipulated in a graphical form, appealing to students with non-verbal learning styles. By providing an authentic context for exploration, students will have the opportunity to manipulate data in ways that parallel the experience of scientists, engineers, and technologists. Also, exploration of these principles can be done in a collaborative environment, encouraging students to promote each other's mastery of the subject matter. Finally, bringing science and math into a technology education environment allows students to experience immediate and practical applications of concepts that they previously only experienced through abstract reading and lecture. This unique approach can help motivate students' further interests in related curricula and careers.

\section{Assessment}

All units will undergo both formative and summative assessment. In addition to iterative review within the development team, each activity will be tested and piloted at six nationally distributed sites during their development and reviewed by both advisory panel members and external evaluators. Teachers will assess and provide feedback on the appropriateness of the materials for 
the subject matter along with critical formative review of the piloting. In addition, teachers will send examples of student work to the Advisory Panel for review.

Assessment of student achievement will include both content knowledge of science and technology concepts covered in the unit as well as evaluations of the graphic communication products. Teachers have the option of testing content knowledge through various formats: traditional testing methods, written assignments, worksheets, or indirectly by assessing the quality of students' graphic communications. Peer evaluations in small groups or as part of whole class presentations offer other alternatives for assessing students. VisTE teacher's materials will give more detailed information concerning how to assess the attainment of learning outcomes.

Because mastery of the underlying technology is not always evident in the final product, success or failure is unlikely to be a binary proposition. Early activities are likely to focus more on applying these tools in a discrete fashion, making it easier for the student to reflect on the outcome and judge their own success. Students should be able to make use of multiple resources (e.g., knowledgeable peers, tutorials, and the teacher) for developing understanding of the capabilities and appropriate application of these tools. In later assignments, evaluation of understanding and use of these tools will be based more on the degree to which larger overall project goals are reached. Evaluation rubrics will be used by both teachers and students for providing intended goals and guided methods for evaluation.

\section{Summary}

The VisTE (Visualization in Technology Education) Project is standards-based, designed to promote higher order thinking and communication skills and the understanding of technology, mathematics, and science through the use of graphic visualization tools. High school students using simple and complex visualization tools to conduct research, analyze, solve problems, and communicate major topics identified in the Standards for Technological Literacy (STL). Twelve discreet units reflecting the twenty STL standards have students engaged in activities such as aerospace engineering design, biotechnology, medical technology, environmental impact studies and the research and development of products, structures, and devices among others.

For a variety of reasons, powerful graphic tools are not commonly employed in the technology education classroom. To address this need, the VisTE Project has designed units that have students focused on developing data-driven and conceptually driven graphic models directly related to technology. Used correctly, both types of modeling are powerful analytic, problem solving and communication tools. Employing these visualization tools in the technology classroom, will help students develop a deeper appreciation and understanding of technology's most important and fundamental concepts and their related scientific and mathematical principles. Students experiencing these units will gain enrichment in key STEM skills and concepts needed for future coursework and careers in engineering and allied technology areas.

\section{Acknowledgements}

This work was supported by the National Science Foundation, grant \#ESI-0137811. 


\section{Bibliography}

1. ITEA, International Technology Education Association. (2000). Technology for all Americans project. ITEA. URL: http://www.iteawww.org/AA/TAA.html

2. Wiebe, E. N. (1992). Scientific visualization: An experimental introductory course for scientific and engineering students. Engineering Design Graphics Journal, 56(1), 39-44.

3. NCSDPI, NC State Department of Public Instruction. (2000). Scientific and technical visualization I (Curriculum T\&I 7922): State of North Carolina.

4. Clark, A. C., \& Wiebe, E. N. (2000). Scientific visualization for secondary and post-secondary education. The Journal of Technology Studies, 26(1), 24-32.

5. Wiebe, E. N., \& Clark, A. C. (1998). Evolving technical graphics in the high schools: A new curriculum in scientific visualization. Engineering Design Graphics Journal, 62(2), 4-15.

\section{Biography}

\section{ERIC N. WIEBE}

Dr. Wiebe is an Assistant Professor in the Graphic Communications Program at NC State University. He has authored or co-authored four texts on technical graphics and has been involved in Computer-Aided Design (CAD)/3D modeling development and use since 1986. During the past nine years, he has worked on the integration of scientific visualization concepts and techniques into both secondary and post-secondary education. Dr. Wiebe has been a member of the EDG Division of ASEE since 1989.

\section{AARON C. CLARK}

Aaron C. Clark is an Assistant Professor of Graphic Communications at North Carolina State University in Raleigh. He received his B.S. and M.S. in Technology and Technology Education from East Tennessee State University. He earned his doctoral degree from NC State University. His teaching specialty is in introductory engineering drawing, with emphasis in 3-D modeling and animation. Research areas include graphics education and scientific/technical visualization. He presents and publishes in both vocational/technology education and engineering education.

\section{MIRIAM FERZLI}

Is a Ph.D. candidate in science education in the Department of Mathematics, Science, and Technology Education at NC State University. Miriam has B.S. degrees in both biology and English and does research that merge these areas with science and technology education. As a Research Associate with the VisTE project, her role is to develop curriculum materials in collaboration with the PI's.

\section{RACHEL MCBROOM}

Is a Ph.D. candidate in science education in the Department of Mathematics, Science, and Technology Education at NC State University. Rachel has B.S. degrees in both chemistry and science education as well as a Masters in Science Education. As a Research Associate with the VisTE project, her role is to use her background in science education to develop curriculum materials in collaboration with the PI's. 